\title{
Prevention of pneumococcal infection in children with homozygous sickle cell disease
}

\author{
A B JOHN, A RAMLAL, H JACKSON, G H MAUDE, A WAIGHT SHARMA, G R SERJEANT
}

\begin{abstract}
The efficacy of prophylactic penicillin and of 14 valent pneumococcal vaccine in preventing pneumococcal infection in homozygous sickle cell (SS) disease was investigated in 242 children aged 6 months to 3 years at entry. In the first five years of the trial there were 11 pneumococcal infections in the pneumococcal vaccine treated group, 10 by serotypes present in the vaccine. Type 23 accounted for five of these, and there was evidence of higher infection rates in those given the vaccine before age 1. No pneumococcal isolations occurred in the penicillin group while receiving penicillin, although four isolations occurred within one year of stopping penicillin.

Probably the most effective prophylaxis against pneumococcal infection requires penicillin beyond the age of 3 . The age at which pneumococcal vaccine should be given must await further data on antibody response and clinical efficacy in these patients.
\end{abstract}

\section{Introduction}

Pneumococcal infection is a major cause of morbidity and mortality in homozygous sickle cell (SS) disease. The increased risk of pneumococcal meningitis has been estimated as roughly 600 times that in the general population, ${ }^{1}$ and the period of greatest risk appears to be before the age of $2 .^{23}$

\footnotetext{
Medical Research Council Laboratories and Department of Microbiology, University of the West Indies, Kingston, Jamaica

A B JOHN, MB, MRCP, member of scientific staff, MRC laboratories A RAMLAL, DM, member of scientific staff, MRC laboratories

H JACKSON, SRN, public health nurse, MRC laboratories

G H MAUDE, BA, MSC, statistician, MRC laboratories

A WAIGHT SHARMA, BSC, lecturer in microbiology

G R SERJEANT, MD, FRCP, director of MRC laboratories

Correspondence and requests for reprints to: Professor Graham R Serjeant, Medical Research Council Laboratories, University of the West Indies, Mona, Kingston 7, Jamaica WI.
}

Prophylaxis against this complication depends on penicillin or pneumococcal vaccines. Penicillin prophylaxis has the problems of compliance, penicillin resistant pneumococci, inhibition of naturally acquired immunity, and doubts on the necessary duration of penicillin coverage. Pneumococcal vaccine has the problems of pneumococcal serotypes not being represented within the vaccine, the poor antigenicity of some serotypes, and the poor antibody response in young children when this protection is most needed.

The vaccine is recommended for children over the age of 2, although the clinical efficacy is unknown in children with SS disease immunised before or even after this age. There are also no data available on the efficacy of penicillin prophylaxis against infection at this age. A randomised controlled trial comparing the efficacy of pneumococcal vaccine and of prophylactic penicillin in young children was therefore begun in Jamaica in May 1978. In view of the topical interest of this study and the striking early results we present an interim report covering the first five years.

\section{Patients and methods}

The patients attended the sickle cell clinics of the University Hospital of the West Indies, Kingston. The cohort clinic follows up all children with sickle cell disease who were detected during the screening of 100000 consecutive normal deliveries at the main government maternity hospital (Victoria Jubilee Hospital) between 1973 and 1981 . The hospital clinic follows up predominantly patients with symptoms referred to the university hospital. Methods of follow up differ, the cohort clinic observing all children at monthly intervals to 6 months, two monthly intervals to 1 year, and three monthly intervals thereafter, whereas patients attending the hospital clinic are reviewed every four to six months or more frequently if clinically indicated. Both clinics are operated by the staff of the MRC laboratories and both attempt to trace defaulting cases, although efforts are generally more rigorous in the cohort study.

The pneumococcal prevention study began in May 1978. A $2 \times 2$ factorial design was used to compare $(a)$ the response to pneumococcal vaccine with that to Haemophilus influenzae type $B$ vaccine as a capsular polysaccharide antigen control and $(b)$ the effect of penicillin with that of no penicillin. The pneumococcal vaccine was a 14 valent type (Merck, Sharpe, and Dohme Laboratories lot 724-5) containing $50 \mu \mathrm{g}$ of each of the following Danish types of purified pneumococcal 
polysaccharide antigens: $1,2,3,4,6 \mathrm{~A}, 7 \mathrm{~F}, 8,9 \mathrm{~N}, 12 \mathrm{~F}, 14,18 \mathrm{C}, 19 \mathrm{~F}$, $23 \mathrm{~F}$, and 25 . The study groups were loaded in favour of the supposedly active treatments, and patients were randomised in groups of nine, four being allocated to pneumococcal vaccine and penicillin (group 1), two to pneumococcal vaccine without penicillin (group 2), two to $H$ influenzae B vaccine with penicillin (group 3 ), and one to $H$ influenzae B vaccine alone (group 4). Children with documented pneumococcal infection or splenectomy before the study were excluded.

TABLE I-Admissions to trial by treatment group

\begin{tabular}{lcc}
\hline & \multicolumn{2}{c}{ No of patients } \\
\cline { 2 - 3 } Treatment group & $\begin{array}{c}\text { Original } \\
\text { randomisation }\end{array}$ & $\begin{array}{c}\text { After revision } \\
\text { of protocol }\end{array}$ \\
\hline 1 (penicillin + 14 valent pneumococcal vaccine) & 104 & 97 \\
2 (14 valent pneumococcal vaccine alone) & 55 & 62 \\
3 (penicillin + Haemophilus influenzae B vaccine) & 55 & 46 \\
4 (Haemophilus influenzae B vaccine alone) & 28 & 27 \\
\hline Total & 242 & 242 \\
\hline
\end{tabular}

TABLE II-Admissions to trial by age group

\begin{tabular}{lrrrr}
\hline & \multicolumn{3}{c}{ Age at entry (months) } & \\
\cline { 2 - 4 } & $6-11$ & $12-23$ & $24-35$ & Total \\
\hline $\begin{array}{l}\text { No of patients } \\
\text { Patient years at risk }\end{array}$ & 130 & 73 & 39 & 242 \\
\hline
\end{tabular}

necessary for 16 patients, eight of whom lived at remote addresses and eight of whom entered between 31 and 35 months of age, which would have resulted in too short a treatment period to assess efficacy. These 16 were assigned to the corresponding vaccine groups without penicillin. The cohort clinic contributed $185(76 \%)$ of the patients and the hospital clinic $57(24 \%)$.

Patients were subsequently closely monitored in their respective clinics, blood cultures being performed in feverish illnesses and at necropsy. Samples for blood culture were inoculated immediately into a brain-heart infusion or into thiol blood culture medium if patients had received penicillin and incubated generally within 30 minutes. Pneumococcal isolations were expressed as incidence rates of pneumococcal infection per 100 patient years at risk, and the difference between trial groups was assessed by the Mantel-Haenszel $\chi^{2}$ test.

\section{Results}

The trial was terminated prematurely in 25 children owing to splenectomy in 20 , emigration in four, and the clinical decision to use prophylactic penicillin in one child with recurrent pneumococcal meningitis (case 11 ; table III). In these cases results up to the time of leaving the study were included in the analysis. There were seven deviations from the protocol caused by refusal to take penicillin after two and four injections (two), death before institution of randomised treatment (one), failure to treat with penicillin because of an error in age (one), inadvertent administration of penicillin to patients joining the study between 31 and 35 months of age (two), and removal to an inaccessible address, so that penicillin had to be stopped (one). These cases were analysed according to their protocol.

Adverse reactions to pneumococcal vaccine were uncommon but included mild fever lasting one to two days, local pain, and swelling.

TABLE III-Details of pneumococcal septicaemias

\begin{tabular}{|c|c|c|c|c|c|c|c|}
\hline Case & $\begin{array}{l}\text { Treatment } \\
\text { group }\end{array}$ & Sex & $\begin{array}{l}\text { Age at entry } \\
\text { (months) }\end{array}$ & $\begin{array}{l}\text { Age at isolation } \\
\text { (months) }\end{array}$ & $\begin{array}{l}\text { Pneumococcal } \\
\text { serotype }\end{array}$ & Additional clinical features & Outcome \\
\hline $\begin{array}{r}1 \\
2 \\
3 \\
4 \\
5 \\
6 \\
7 \\
8 \\
9 \\
10 \\
11 \\
12 \\
13\end{array}$ & $\begin{array}{l}1 \\
1 \\
1 \\
1 \\
1 \\
1 \\
1 \\
2 \\
2 \\
2 \\
2 \\
4 \\
4\end{array}$ & $\begin{array}{l}M \\
M \\
\mathrm{~F} \\
\mathrm{M} \\
\mathrm{F} \\
\mathrm{M} \\
\mathrm{F} \\
\mathrm{M} \\
\mathrm{F} \\
\mathrm{F} \\
\mathrm{F} \\
\mathrm{F} \\
\mathrm{M}\end{array}$ & $\begin{array}{r}6 \\
6 \\
7 \\
9 \\
21 \\
21 \\
22 \\
6 \\
9 \\
23 \\
27 \\
6 \\
31\end{array}$ & $\begin{array}{l}40 \\
37 \\
41 \\
46 \\
65 \\
52 \\
58 \\
39 \\
12 \\
56 \\
54 \\
18 \\
92\end{array}$ & $\begin{array}{r}6 \\
23 \\
23 \\
23 \\
9 \\
36 \\
9 \\
23 \\
33 \\
19 \\
23 \\
19 \\
6\end{array}$ & $\begin{array}{l}\text { Meningitis, dactylitis } \\
\text { Pneumonia } \\
\text { Otitis media, gastroenteritis } \\
\text { Meningitis } \\
\text { Otitis media } \\
\text { Pneumonia } \\
\text { Dactylitis, impetigo } \\
\text { Pneumonia } \\
\text { Meningitis } \\
\text { Meningitis }\end{array}$ & $\begin{array}{l}\text { Alive } \\
\text { Died } \\
\text { Alive } \\
\text { Alive } \\
\text { Died } \\
\text { Alive } \\
\text { Alive } \\
\text { Alive } \\
\text { Alive } \\
\text { Alive } \\
\text { Alive* } \\
\text { Alive } \\
\text { Alive }\end{array}$ \\
\hline
\end{tabular}

*Recurrent pneumococcal septicaemia.

The study was confined to children with SS disease, the diagnosis being based on haemoglobin bands in the positions of $\mathrm{HbS}$ and $\mathrm{HbF}$ on alkali and acid haemoglobin electrophoresis at birth, compatible $\mathrm{HbA}_{2}$ values later, and family studies where possible. Subsequent revision of genotype led to the withdrawal of 18 children admitted to the study.

Ethical approval was obtained and the objectives of the study carefully explained before asking for parental consent. A few parents declined to join the study, requesting instead a specific treatment. Otherwise all children with SS disease aged 6 months to 3 years continued to be admitted to the study, the hospital and cohort clinics using independent randomisation schedules. The 14 valent pneumococcal vaccine and $H$ influenzae $\mathrm{B}$ vaccine were each given as a single intramuscular dose of $0.5 \mathrm{ml}$ on admission to the study. Penicillin was given as long acting benzathine penicillin in a dose of 600000 units by monthly intramuscular injections at home, which ensured $100 \%$ compliance. As these injections are painful penicillin was confined to children between the ages of 6 months and 3 years, this decision being influenced by the pretrial finding that nine out of 10 pneumococcal infections occurred before the age of 30 months (ages 5, 7, 9, 9, 12, 16, 22, 22, 29, and 64 months).

A total of 265 children were randomised to the four study groups, but 23 of these were subsequently withdrawn, mostly due to revision of genotype. The remaining 242 children ( 128 boys, 114 girls) were admitted between May 1978 and August 1983. Tables I and II give the results of randomisation to treatment and the age distribution of the children at entry. A revision of protocol withholding penicillin was
Penicillin was well tolerated, and no confirmed allergic reactions occurred.

During the five years there were 13 isolations of the pneumococcus from blood or cerebrospinal fluid (table III), all of which were sensitive to penicillin; only one serotype (type 36 ) was not represented in the vaccine. The pneumococcal isolations analysed by study group (table IV; figure) indicated that 11 occurred in children given the pneumococcal vaccine and seven in children randomised to the penicillin group. When the data in table IV were re-expressed by age group (table V) it was apparent that no pneumococcal isolations had occurred while the children were actually receiving penicillin, although

TABLE IV-Pneumococcal isolations according to study group expressed as isolations per patient years at risk (percentages in parentheses-incidence rate per 100 patient years at risk)

\begin{tabular}{lccc}
\hline & $\begin{array}{c}14 \text { Valent pneumococcal } \\
\text { vaccine }\end{array}$ & $\begin{array}{c}\text { Haemophilus influenzae } \\
\text { B vaccine }\end{array}$ & Overall \\
\hline $\begin{array}{l}7 / 275(2 \cdot 5) \\
\text { Penicillin* }\end{array}$ & $\begin{array}{l}0 / 125 \\
2 / 106(1 \cdot 9)\end{array}$ & $\begin{array}{l}7 / 400(1 \cdot 8) \\
6 / 280(2 \cdot 1)\end{array}$ \\
\hline Ove penicillin & $11 / 449(2 \cdot 4)$ & $2 / 231(0 \cdot 9)$ & $13 / 680(1 \cdot 9)$ \\
\hline
\end{tabular}

*Penicillin terminated at third birthday. 


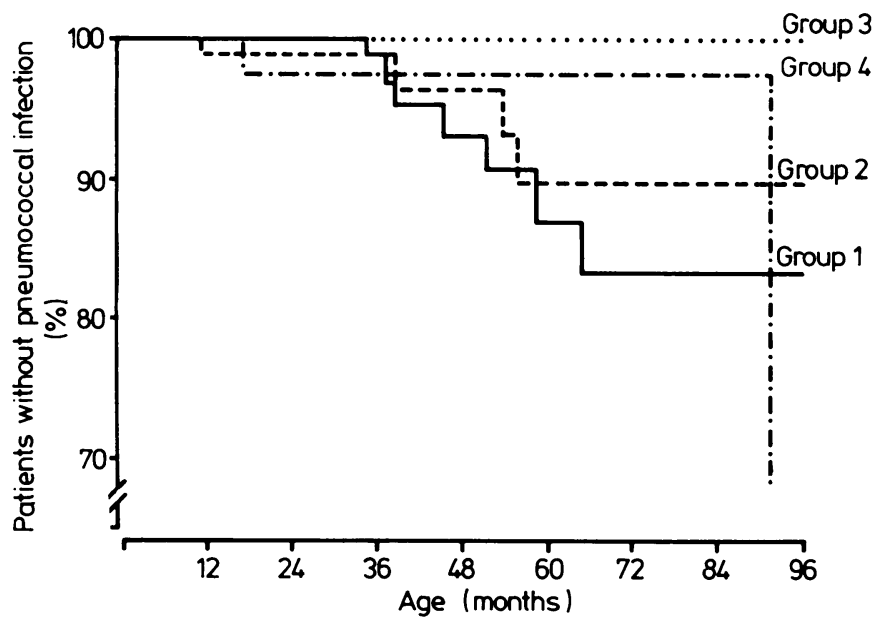

Life table analysis depicting incidence of pneumococcal infections in treatment group 1 (pneumococcal vaccine and penicillin until age 3 ), group 2 (pneumococcal vaccine alone), group 3 (Haemophilus influenzae B vaccine and penicillin until age 3 ), and group 4 (Haemophilus influenzae B vaccine alone). Numbers of patients entering trial were $97,62,46$, and 37 and numbers still under observation and without pneumococcal infection by 60 months $25,22,10$, and 14 in groups $1,2,3$, and 4 respectively. Vertical line at 92 months in group 4 represents pneumococcal event in only child still in that group at that age.

four isolations had occurred within 11 months of stopping penicillin. Table $\mathrm{V}$ also shows that even in the group given pneumococcal vaccine alone the incidence rate was greater in children aged over 3 years, in contrast to the pretrial finding that most isolations occurred before the age of 2 . Children from the hospital clinic tended to be recruited at a later age, but after allowance for this there were no differences in results between children recruited from the two sources.

TABLE V-Pneumococcal isolations according to study and age group expressed as isolations per patient years at risk (percentages in parentheses-incidence rate per 100 patient years at risk)

\begin{tabular}{|c|c|c|c|c|}
\hline \multirow[b]{2}{*}{ Age group } & \multicolumn{2}{|c|}{ Penicillin* } & \multicolumn{2}{|c|}{ No penicillin } \\
\hline & $\begin{array}{c}14 \text { Valent } \\
\text { pneumococcal } \\
\text { vaccine }\end{array}$ & $\begin{array}{l}\text { Haemophilus } \\
\text { influenzae } \\
\text { vaccine }\end{array}$ & $\begin{array}{l}14 \text { Valent } \\
\text { pneumococcal } \\
\text { vaccine }\end{array}$ & $\begin{array}{c}\text { Haemophilus } \\
\text { influenzae } \\
\text { vaccine }\end{array}$ \\
\hline $\begin{array}{l}6 \text { months to } 3 \text { years } \\
\text { Over } 3 \text { years }\end{array}$ & $\begin{array}{l}0 / 163 \\
7 / 112(6 \cdot 2)\end{array}$ & $\begin{array}{l}0 / 80 \\
0 / 45\end{array}$ & $\begin{array}{l}1 / 82(1 \cdot 2) \\
3 / 92(3 \cdot 3)\end{array}$ & $\begin{array}{l}1 / 50(2.0) \\
1 / 56(1.8)\end{array}$ \\
\hline
\end{tabular}

*Penicillin terminated at third birthday.

Comparison of penicillin with no penicillin, after allowance for vaccine group and age group, gave a Mantel-Haenszel $\chi^{2}$ value of 0.02 . When the analysis was restricted to the age group below 3 , in which penicillin was given, the $\chi^{2}$ value was 1.33 . Comparison of pneumococcal vaccine with $H$ influenzae $\mathrm{B}$ vaccine after allowance for penicillin group and age group gave a $\chi^{2}$ value of $1 \cdot 16$. These comparisons were also made $(a)$ using the original randomisation groups (before revising the protocol) and (b) grouping by treatment actually received; the results for $\chi^{2}$ were similar. None of these values was significant at the $5 \%$ level, but the power of the tests was limited by the small number of isolations.

Ten of the pneumococcal infections in the pneumococcal vaccine treated group were by serotypes present in the vaccine and were therefore "vaccine breakthroughs." Type 23, which is known to be poorly antigenic, accounted for five of the 10 infections. It was important to know whether these breakthrough infections were confined to children given vaccine at a very young age, and analysis indicated that among the 62 children given only pneumococcal vaccine, those given the vaccine in their first, second, and third years had incidence rates (isolations per 100 patient years at risk) of $3 \cdot 4,1 \cdot 5$, and $2 \cdot 0$ respectively. These data were very limited but were compatible with children given the vaccine before 1 year of age being at greater risk of septicaemia.

\section{Discussion}

No pneumococcal isolations occurred in the children receiving prophylactic penicillin. Such prophylaxis may be given by mouth or by monthly injections of slow release benzathine peni- cillin, but owing to difficulties with compliance no trials have been reported. ${ }^{4}$ In this study compliance was assured by a domiciliary programme with monthly injections. These injections are painful and the penicillin arm of the study was therefore terminated at 36 months, sufficient to cover the high risk period of pneumococcal infections as judged from the pretrial findings. The transient pain of the injection of the depot preparation was the only important side effect of penicillin, no patient having a history of penicillin allergy or developing allergy during the trial. The theoretical risk of inducing penicillin insensitive organisms does not appear to be important in the short term. Such organisms may be important in closed or secluded communities, relatively resistant strains of pneumococcus being clinically important in Australia and New Guinea, ${ }^{5}$ American Indian communities, ${ }^{6}$ and South Africa. ${ }^{7}$ Resistant pneumococci, judged by the failure of clinical pneumococcal disease to respond to penicillin, have not been recognised in the Caribbean.

A more immediate criticism of the use of monthly benzathine penicillin would be the apparent failure of protective concentrations to persist in the blood for the second half of the four week period between injections, ${ }^{8}$ and further studies are needed to corroborate this finding. If confirmed, this would be an argument in favour of oral penicillin, in which administration four times daily should maintain more even therapeutic values. If, however, concentrations in the blood were so low as to offer no protection for half of the period between injections, pneumococcal infections might have been expected to occur in the penicillin treated group but to be confined to the second half of each cycle. In practice, no pneumococcal infections occurred in the children while receiving penicillin prophylaxis, although four isolations occurred within 11 months of stopping penicillin at the age of 36 months. This disturbing clustering of events raises the possibility that effective protection being stopped at the age of 3 rendered the group hypersusceptible to subsequent infections because of lack of any acquired immunity. This hypothesis could be tested by observing the pneumococcal type specific antibody values in groups matched for age and sex given and not given penicillin prophylaxis.

By contrast with the apparent effectiveness of penicillin, the pneumococcal vaccine was unsatisfactory. There were 11 pneumococcal isolations in the group given pneumococcal vaccine, and 10 of these were types represented in the vaccine. Type 23 accounted for five of these 10 vaccine failures, and types 6,19 , and 23 have accounted for most of the vaccine failures recognised elsewhere. ${ }^{9-11}$ This is consistent with observations that types $4,6,14,19$, and 23 are poorly antigenic as assessed by antibody response. ${ }^{11-15}$ The antigenicity of these serotypes is poor regardless of age, although generally the response to polysaccharide antigens improves with age. Nevertheless, antibody responses to some serotypes have been documented in children immunised as early as 6 months, ${ }^{121316}$ and some serotype antigens are quite effective in children before the age of 2 years. Our findings suggest that such antibody levels may not confer clinical protection and that vaccine failures may be more common in-but not confined to-children immunised before the age of 2 years.

It is also of interest that the age specific incidence rates for pneumococcal infections were different during the study from those in the pretrial period. In the penicillin groups this could be attributed to effective treatment which delayed the age of penumococcal infections. Even in the group treated by pneumococcal vaccine alone, however, three out of four infections occurred after 3 years of age compared with eight out of 10 before 2 years previous to the trial. A possible interpretation of this is a changing natural pattern of pneumococcal infection or that the vaccine had given protection sufficient to delay the onset of infection.

Our results do not conflict with other, uncontrolled observations. A study with octavalent vaccine ${ }^{15}$ reported no infections among 77 immunised patients compared with eight infections among 106 non-immunised patients in a two year observation period. This difference was significant, although the small number of children in the high risk group (15 immunised, 24 non- 
immunised; age 2-6 years) and the high incidence rate of infection among the non-immunised group cast doubt on the validity of the comparison group. An uncontrolled trial with 14 valent vaccine over two years ${ }^{11}$ reported an incidence rate for pneumococcal sepsis of $4 \cdot 4 / 100$ patient years compared with incidence rates in historical comparison groups of $5 \cdot 8,{ }^{2}$ and $9 \cdot 0^{11}$ in children under 5 . These very high incidence rates compared with those noted in this study suggest either that pneumococcal disease is much more common in North America or, more likely, that serious election biases influenced the patients joining such studies.

Our data suggest that pneumococcal vaccine given in the mode and at the ages detailed does not protect against pneumococcal infection. The use of booster doses or adjuvants may improve antibody response and clinical efficacy, but experimental confirmation is needed. In the mean time penicillin offers the most effective prophylaxis and must continue beyond the age of 3 years. Pneumococcal vaccine should be given as late as possible during the period of penicillin coverage.

The pneumococcal and $H$ influenzae $\mathrm{B}$ vaccines were donated by Merck, Sharpe, and Dohme under the NIAID collaborative pneumococcal vaccine study programme, coordinated by Dr James C Hill, of the National Institutes of Health. Mr Richard Peto provided valuable advice on study design.

\section{References}

${ }^{1}$ Barrett-Connor E. Bacterial infection and sickle cell anemia. Medicine $1971 ; 50: 97-112$.

${ }^{2}$ Overturf GD, Powars D, Baraff LJ. Bacterial meningitis and septicaemia in sickle cell disease. Am $\mathcal{F}$ Dis Child 1977;131:784-7.

${ }^{3}$ Rogers DW, Vaidya S, Serjeant GR. Early splenomegaly in homozygous sickle cell disease: an indicator of susceptibility to infection. Lancet 1978;ii :963-5.
' Landesman SH, Rao SP, Ahonkhai VI. Infections in children with sickle cell anemia. Special reference to pneumococcal and salmonella infections. Am $\mathcal{F}$ Pediatr Hematol Oncol 1982;4:407-15.

5 Hansman D, Devitt L, Miles H, Riley I. Pneumococci relatively insensitive to penicillin in Australia and New Guinea. Med f Aust 1974;ii:353-6.

${ }^{6}$ Tempest B, Carney JP, Eberle B. Distribution of the sensititivities to penicillin of types of Diplococcus pneumoniae in an American Indian population. I Infect Dis 1974;130:67-9.

: Appelbaum PC, Bhamjee A, Scragg JN, Hallett AF, Bowen AJ, Cooper RC. Streptococcus pneumoniae resistant to penicillin and chloramphenicol. Lancet 1977; ii:995-7.

* Ginsberg CM, McCracken GH, Zweighaft TC. Serum penicillin concentrations after intramuscular administration of benzathine penicillin $\mathrm{G}$ in children. Pediatrics $1982 ; 69: 452-4$.

9 Ahonkhai VI, Landesman SH, Fikrig SM, et al. Failure of pneumococcal vaccine in children with sickle-cell disease. $N$ Engl f Med 1979;301: 26-7.

${ }^{10}$ Broome CV, Facklam RR, Fraser DW. Pneumococcal disease after pneumococcal vaccination. An alternative method to estimate the efficacy of pneumococcal vaccine. $N$ Engl f Med 1980;303:549-52.

11 Overturf GD, Rigau-Perez JG, Honig G, et al. Pneumococcal polysaccharide immunization of children with sickle cell disease. II. Serologic response and pneumococcal disease following immunization. $\mathrm{Am} \mathcal{F}$ Pediatr Hematol Oncol 1982 ;4:25-35.

12 Borgono JM, McLean AA, Vella PP, et al. Vaccination and revaccination with polyvalent pneumococcal polysaccharide vaccines in adults and infants. Proc Soc Exp Biol Med 1978;157:148-54.

13 Cowan MJ, Ammann AJ, Wara DJ, et al. Pneumococcal polysaccharide immunization in infants and children. Pediatrics 1978;62:721-7.

14 Weibel RE, Vella PP, McLean AA, Woodhour Af, Davidson WL, Hilleman MR. Studies in human subjects of polyvalent pneumococcal vaccines. Proc Soc Exp Biol Med 1977;156:144-50.

${ }^{15}$ Ammann AJ, Addiego J, Wara DW, Lubin B, Smith WB, Mentzer WC. Polyvalent pneumococcal-polysaccharide immunization of patients with sickle-cell anemia and patients with splenectomy. $N$ Engl f Med $1977 ; 297: 897-900$.

16 Buchanan GR, Schiffman G. Antibody responses to polyvalent pneumococcal vaccine in infants with sickle cell anemia. 7 Pediatr $1980 ; 96: 264-6$

(Accepted 22 March 1984)

\title{
Pelvic infection: a comparison of the Dalkon shield and three other intrauterine devices
}

\author{
R SNOWDEN, B PEARSON
}

\begin{abstract}
A detailed analysis was undertaken of reports of possible pelvic infection in relation to the use of four commonly fitted intrauterine contraceptive devices during 1971 to 1978 in the United Kingdom. The four devices were the Dalkon shield, Lippes loops 3C and 2D, and the Gravigard (copper 7), and data used were those collected systematically through the UK intrauterine device research network. Prospective reports that the Dalkon shield was uniquely related to high levels of infection when compared with other intrauterine devices were not substantiated in this prospective study among 13349 users. Though some factors such as social class and previous experience of abortion appeared to influence the rate of infection, the type of intrauterine
\end{abstract}

University of Exeter, Exeter EX4 6DT

R SNOWDEN, PHD, director, Institute of Population Studies

B PEARSON, MSC, lecturer in economic and social statistics

Correspondence to: Dr R Snowden. device being worn did not appear to be a significant factor. Various methods of analysis were used including life table, regression, and discriminant analysis, using information relating to the type of intrauterine device worn, the characteristics of the user, the fitting centre, and the pattern of diagnosis and treatment of reported or suspected pelvic infection.

The results of this study suggest that fears that the Dalkon shield may be associated with a higher incidence of pelvic infection than other intrauterine devices may have been unjustified.

\section{Introduction}

For almost a decade the Dalkon shield intrauterine device has been the subject of inquiry about its relation to pelvic infection, which has sometimes caused infertility, septic spontaneous abortion, and even death. Some reports have condemned the Dalkon shield ${ }^{1}$ while others have claimed that the Dalkon shield is itself the victim of unjustified claims. ${ }^{2}$ One major problem has been the absence of prospective data among a sufficient number of women wearing this intrauterine device. 